\title{
Attenuation of Ribosomal Protein S6 Phosphatase Activity in Chicken Embryo Fibroblasts Transformed by Rous Sarcoma Virus
}

\author{
BORJA BELANDIA, ${ }^{1}$ DAVID BRAUTIGAN, ${ }^{2}$ AND JORGE MARTÍN-PÉREZ ${ }^{1 *}$ \\ Instituto de Investigaciones Biomédicas, Consejo Superior de Investigaciones Científicas, 28029 Madrid, \\ Spain, ${ }^{1}$ and J. W. Wilson Laboratory, Section of Biochemistry, Brown University,
} Providence, Rhode Island 02912

Received 12 August 1993/Returned for modification 7 September 1993/Accepted 19 October 1993

\begin{abstract}
In chicken embryo fibroblasts, phosphorylation of the $40 S$ ribosomal protein $S 6$ increases during $G_{1}$ but returns to basal level by mitosis. In contrast, in Rous sarcoma virus (RSV)-transformed fibroblasts, S6 remains highly phosphorylated throughout mitosis. This study investigated the mechanism by which RSV alters the pattern of S6 phosphorylation. Pulse-chase experiments demonstrate that phosphate turnover in S6 is rapid in normal cells and in cells infected with an RSV transformation-defective virus. In contrast, phosphate turnover in S6 is severely reduced in cells infected with temperature-sensitive RSV at a temperature permissive for transformation, indicating a diminished S6 phosphatase activity. Fractionation of cell lysates by DEAE chromatography showed an almost threefold lower S6 phosphatase activity in RSV-transformed versus normal cells. The S6 phosphatase was sensitive to inhibitor 2 and specifically recognized by an antibody to type 1 phosphatase (PP1). The S6 phosphatase activity recovered by immunoprecipitation of PP1 was threefold lower in transformed cells, but the steady-state level of expression and the rate of synthesis of PP1 were not altered by oncogenic transformation. Together, the results show that transformation by RSV reduced the S6-PP1 activity.
\end{abstract}

Reversible protein phosphorylation plays a central role in the control of cell proliferation and depends on the relative activities of protein kinases and phosphatases. The tyrosine kinase activity exhibited by a number of growth factor receptors and oncogene products is critical for induction of cell growth and malignant transformation (for a review, see reference 41). Tyrosine phosphorylation of cellular proteins represents a minor fraction of total protein phosphorylation (26). Yet, through a series of cascades not fully characterized, tyrosine phosphorylation leads to the activation of a number of serine and threonine kinases. As a result, serine (threonine) protein phosphorylation increases, constituting the bulk of cellular protein phosphorylation in response to growth factors and oncogene products (for a review, see reference 46 ).

An early cellular event after mitogenic stimulation or viral transformation is the multiple and ordered phosphorylation of the $40 \mathrm{~S}$ ribosomal protein S6 $(5,35,36)$. Phosphorylation of $S 6$ seems to be a prerequisite for $G_{1}$ progression $(45,47)$. It is controlled by the opposing activities of the mitogenactivated S6 kinase (for a review, see reference 19) and protein phosphatase type 1 (PP1) $(2,39)$. The S6 kinase itself is regulated by phosphorylation, and type $2 \mathrm{~A}$ phosphatase (PP2A) specifically inactivates this and other kinases in the cascade $(3,21)$.

It is clear that protein phosphatases play a fundamental role in the control of cellular growth and differentiation (for reviews, see references $7,9,13,24$, and 40). Among serine and threonine protein phosphatases, the PP1 catalytic subunit, a $37-\mathrm{kDa}$ protein, is one of the most highly conserved enzymes in eukaryotes $(7,13,15,16)$. PP1 is essential for

${ }^{*}$ Corresponding author. Mailing address: Instituto de Investigaciones Biomédicas, Consejo Superior de Investigaciones Científicas, Arturo Duperier 4, 28029 Madrid, Spain. Phone: 34-1-5854603. Fax: 34-1-5854587. completion of mitosis in lower eukaryotes such as Aspergillus nidulans and Schizosaccharomyces pombe. Furthermore, genetic studies have shown that mutation of genes homologous to the mammalian PP1 causes mitotic defects in chromosomal disjunction and separation of nuclei during anaphase $(8,17,37)$. Also in higher eukaryotes, microinjection of neutralizing anti-PP1 antibodies at the beginning of mitosis blocks cell division at metaphase (20). In addition, PP1 is associated with and controls the dephosphorylation of the retinoblastoma protein $\left(\mathrm{p} 110^{\mathrm{RB}}\right)(18,31)$, whose state of phosphorylation through the cell cycle is important for the control of cell growth (23). In this context, PP1 may be implicated in cell proliferation and tumor repression.

The nucleotide and amino acid sequences of PP1 show significant homology with those of the PP2A catalytic subunit (4). However, the differences at the carboxyl terminal portions of PP1 and PP2A $(4,16)$ have permitted generation of specific antipeptide sera for PP1, which does not interfere with its enzymatic activity $(12,29,32,39)$. Here, we have examined in chicken embryo fibroblasts the effect of Rous sarcoma virus (RSV) transformation on the S6 phosphorylation and found evidence for a decrease in the specific activity of PP1-S6 phosphatase.

\section{MATERIALS AND METHODS}

Cell culture and labeling. CEF cells were cultured in Dulbecco's modified Eagle's medium (DMEM) supplemented with 5\% newborn calf serum (NBCS; Sera-Lab Limited, Sussex, United Kingdom), $1 \%$ chicken serum (Sera-Lab Limited), and antibiotics at $41.5^{\circ} \mathrm{C}$. They were infected independently with different mutants of the RSV viral stocks: wild-type Schmidt-Ruppin subgroup, strain A (wildtype v-Src; a gift of R. L. Erikson, Harvard University); $t s-N Y 72-4$, a temperature-sensitive mutant of v-Src, and the $t d$-NY3-15, an N-terminal deletion mutant defective for 
transformation of $\mathrm{v}$-Src (both viral mutants were a gift of $\mathrm{H}$. Hanafusa, Rockefeller University) (22). Cells were used for experiments two passages after infection.

For labeling cells with ${ }^{32} \mathrm{P}_{\mathrm{i}}$, cultures in $90-\mathrm{mm}$-diameter dishes were incubated with $0.4 \mathrm{mCi}$ of ${ }^{32} \mathrm{P}_{\mathrm{i}}$ (carrier free; ICN Biomedicals, Irvine, Calif.) $\mathrm{ml}^{-1}$ in $5 \mathrm{ml}$ of phosphate-free medium for the appropriate period of time. For labeling with $\left[{ }^{35} \mathrm{~S}\right]$ methionine, cells cultured in $60-\mathrm{mm}$-diameter dishes were preincubated for $30 \mathrm{~min}$ in $2 \mathrm{ml}$ of methionine-free medium and then radiolabeled with $200 \mu \mathrm{Ci}$ of $\left[{ }^{35} \mathrm{~S}\right]$ methionine (Translabel; ICN Biomedicals) $\mathrm{ml}^{-1}$ for the time and temperature indicated in each experiment.

Ribosomal protein extraction and analysis of S6 phosphorylation. Ribosomal proteins were extracted from cultured cells, and phosphorylation of S6 was analyzed by twodimensional gel electrophoresis or by sodium dodecyl sulfate-polyacrylamide gel electrophoresis (SDS-PAGE) as previously described $(30,34,42)$.

Assay of S6 protein phosphatase activity. The test of the S6 protein phosphatase activity was performed with $40 \mathrm{~S}$ rat liver ribosomal subunits prepared by zonal centrifugation and phosphorylated with $\left[\gamma^{-32} \mathrm{P}\right] \mathrm{ATP}$ (ICN Biomedicals; $7,000 \mathrm{Ci} / \mathrm{mmol}$ ). Cytosolic extracts were used a source of S6 protein kinase as described elsewhere (34), except that okadaic acid (Boehringer Mannheim) was included in the lysis buffer to a final concentration of $1 \mathrm{nM}$. The ${ }^{32} \mathrm{P}-40 \mathrm{~S}$ ribosomal subunits were repurified by ethanol precipitation and resuspended in $20 \mathrm{mM}$ Tris- $\mathrm{HCl}$ (pH 7.4)-100 mM $\mathrm{KCl}-5 \mathrm{mM} \mathrm{MgCl}-1 \mathrm{mM}$ 2-mercaptoethanol to a final optical density at $A_{260}$ of $15 \mathrm{U} / \mathrm{ml}$, as described elsewhere (34), and used as a phosphatase substrate.

Partial purification of S6 phosphatase from cellular extracts. CEF or CEF-ts-NY72-4 cells grown in seven 90-mmdiameter petri dishes (about $3 \times 10^{7}$ cells) were washed with $5 \mathrm{ml}$ of ice-cold Tris-saline (20 mM Tris- $\mathrm{HCl}$ [pH 7.2], 150 $\mathrm{mM} \mathrm{NaCl}$ ) per dish, and then scraped and resuspended in 1 $\mathrm{ml}$ of ice-cold homogenization buffer $(20 \mathrm{mM}$ Tris- $\mathrm{HCl}[\mathrm{pH}$ 7.2], $15 \mathrm{mM}$ 2-mercaptoethanol, $0.1 \mathrm{mM}$ EDTA, $1 \mathrm{mM}$ phenylmethylsulfonylfluoride) and homogenized with 30 strokes of a Dounce homogenizer with a tight-fitting pestle. The homogenates were centrifuged at $100,000 \times g$ for $2 \mathrm{~h}$, and the supernatants were adjusted to a final concentration of $10 \%$ glycerol and passed over $7 \mathrm{ml}$ of DEAE cellulose (Whatman, DE 52) columns equilibrated with homogenization buffer containing $10 \%$ glycerol. The chromatography was developed with a $60-\mathrm{ml}$ linear gradient from 30 to 300 $\mathrm{mM} \mathrm{NaCl}$. Fractions of $1 \mathrm{ml}$ were collected, and the phosphatase activity was measured in every other fraction.

The eluted $\$ 6$ phosphatase activity was assayed in a final volume of $25 \mu$ l containing $10 \mu$ l of homogenization buffer, 5 $\mu \mathrm{l}$ of the corresponding fraction, and $10 \mu \mathrm{l}$ of ${ }^{32} \mathrm{P}-40 \mathrm{~S}$ ribosomal subunits (optical density at $260 \mathrm{~nm}, 0.15$ ). After incubation for $10 \mathrm{~min}$ at $30^{\circ} \mathrm{C}$, the reaction was stopped by addition of $6 \mu$ l of $5 \times$ SDS-sample buffer; the reaction mixture was boiled for $3 \mathrm{~min}$, and the proteins were resolved by SDS-15\% PAGE (30). The gels were dried and exposed to Kodak X-Omat film at $-70^{\circ} \mathrm{C}$, with the addition of a pair of Cronex Lightning-Plus intensifying screens (Du Pont Co., Wilmington, Del.). Finally, the bands corresponding to ${ }^{32} \mathrm{P}$-S6 were excised and their content in ${ }^{32} \mathrm{P}$ was quantified by scintillation counting. When inhibitor 2 was used, the samples were preincubated at $30^{\circ} \mathrm{C}$ for $10 \mathrm{~min}$ with $1 \mu \mathrm{g}$ of purified inhibitor 2 (48) before the addition of the substrate.

Analysis of PP1 by immunoprecipitation and immunoblotting. Immunoprecipitation and immunoblotting of PP1 from cell extracts were carried out with an anti-PP1-peptide serum

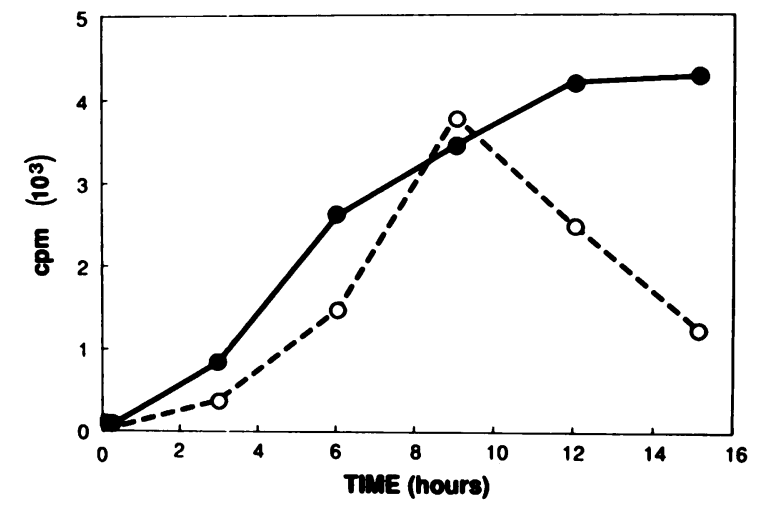

FIG. 1. S6 phosphorylation in normal and RSV-transformed cells. Quiescent cultures of CEF and CEF- $t s-N Y 72-4$ at $41.5^{\circ} \mathrm{C}$ were stimulated by shifting both from 41.5 to $35^{\circ} \mathrm{C}$ plus the addition of $10 \%$ serum to CEF in the presence of $0.4 \mathrm{mCi}$ of ${ }^{32} \mathrm{P}_{\mathrm{i}} \mathrm{ml}^{-1}$. At the indicated times, ribosomes were isolated from cell lysates and loaded in an SDS-15\% PAGE, the ${ }^{32} \mathrm{P}-\mathrm{S} 6$ band was excised, and radioactivity was determined by scintillation counting after autoradiography of the gel. O, CEF; $\odot$, CEF-ts-NY72-4.

generated against the $14 \mathrm{C}$-terminal amino acid residues of PP1c (a gift of A. Olivier and G. Thomas, Friedrich Miescher Institute) as described previously (39).

Assay of phosphorylase $a$ phosphatase activity. Phosphorylase $b$ and phosphorylase kinase were purified from rabbit skeletal muscle and used to prepare $\left[{ }^{32} \mathrm{P}\right]$ phosphorylase $a$ with a specific activity of $3 \times 10^{3}$ to $5 \times 10^{3} \mathrm{dpm} / \mathrm{pmol}(14)$. The protein phosphatase activity of the immunoprecipitates from cell lysates was determined as described previously (39).

\section{RESULTS}

Early studies had suggested that S6 phosphorylation is differentially regulated in normal versus $v$-Src-transformed chicken embryo fibroblasts (33). To examine this possibility more closely, S6 phosphorylation was measured in normal chicken embryo fibroblasts (CEF) following serum stimulation and in CEF-ts-NY72-4, transformed with a temperaturesensitive mutant of p60 $0^{\mathrm{v}-s r c}$, after simultaneously shifting the cell cultures from the nonpermissive temperature $\left(41.5^{\circ} \mathrm{C}\right)$ to the permissive temperature $\left(35^{\circ} \mathrm{C}\right)$. Under these two conditions, cultures grew at similar rates, with a doubling time of $16 \mathrm{~h}$ (data not shown). As shown in Fig. 1, the increase in the incorporation of ${ }^{32} \mathrm{P}$ label into $S 6$ during the $G_{1}$ phase of the cell cycle was comparable in normal and transformed cells. However, whereas in CEF cells the levels of S6 phosphorylation returned to basal levels by mitosis, in CEF-ts-NY724-transformed cells they remained high throughout the time course. The observation suggested that oncogenic transformation could alter the activity of either the kinase or a phosphatase involved in regulating the levels of S6 phosphorylation.

CEF cells transformed by v-Src showed an activation of the S6 kinase comparable to that found when grown with a saturating concentration of serum (6). This result suggested that the high levels of S6 phosphorylation detected in transformed cells (Fig. 1) reflected a decrease of S6 phosphatase activity rather than an increase of S6 kinase activity. To test this hypothesis, we studied the dephosphorylation of $\mathrm{S} 6$ by examining the turnover of the ${ }^{32} \mathrm{P}_{i}$ incorporated into $\mathrm{S} 6$ during the $G_{1}$ phase. In pulse-chase experiments, we could 

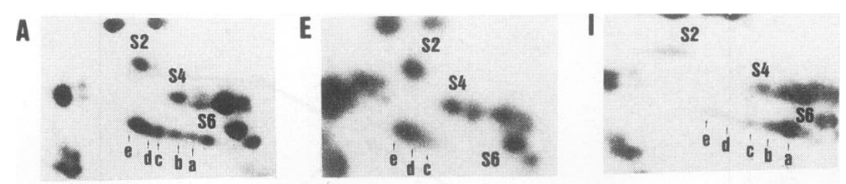

$\mathbf{B}$

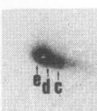

F

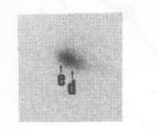

J
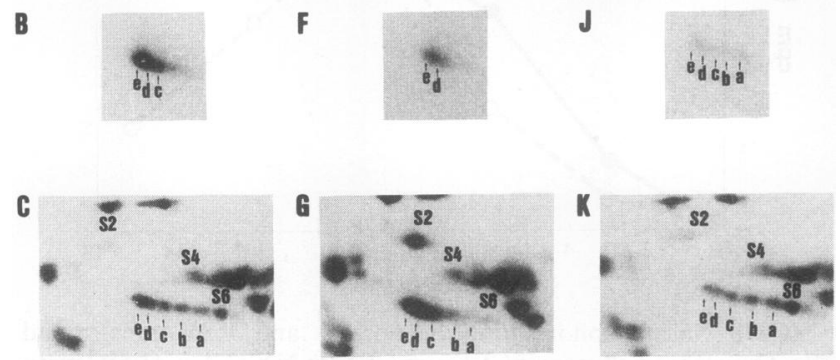

D

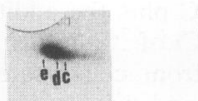

H

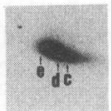

L

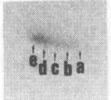

FIG. 2. Pulse-chase labeling of cells to observe turnover of phosphate in S6. Quiescent cultures of CEF and CEF-ts-NY72-4 at $41.5^{\circ} \mathrm{C}$ were stimulated by shifting both to $35^{\circ} \mathrm{C}$ plus the addition of $10 \%$ serum to CEF in the presence of $0.4 \mathrm{mCi}$ of ${ }^{32} \mathrm{P}_{\mathrm{i}} \mathrm{ml}^{-1}$ in phosphate-free DMEM. After $2 \mathrm{~h}, 9 \times 10^{6}$ cells of each type were lysed and the extent of S6 phosphorylation was analyzed by two-dimensional gel electrophoresis. These experiments are depicted by Coomassie blue patterns of CEF (A) and CEF-ts-NY72-4 (C) and by autoradiography of CEF (B) and CEF-ts-NY72-4 (D). For pulse and chase experiments, two other sets of each cell type were washed four times with prewarmed complete DMEM. One set was maintained under stimulated conditions but without ${ }^{32} \mathrm{P}_{\mathrm{i}}$ for another $2 \mathrm{~h}$, and then S6 phosphorylation was analyzed as above: by Coomassie blue patterns of CEF (E) and CEF-ts-NY72-4 (G) and by autoradiography of CEF (F) and CEF-ts-NY72-4 (H). The other set of cells was also chased for $2 \mathrm{~h}$ as described above but at $41.5^{\circ} \mathrm{C}$ and with serum-deprived CEF. Coomassie blue patterns of CEF (I) and CEF-ts-NY72-4 (K) and autoradiography of CEF (J) and CEF-tsNY72-4, (L) are shown.

determine, on the basis of electrophoretic migration by two-dimensional gel electrophoresis (47), the turnover of S6 phosphorylation by comparing the radiolabeling of S6 (autoradiography) to its overall phosphorylation state (Coomassie blue staining pattern).

In quiescent cells, S6 exists mostly in the dephosphorylated state (47; data not shown). Stimulation of cells for $2 \mathrm{~h}$ by the addition of serum or by activation of the $t s-\mathrm{v}-\mathrm{src}$ oncogene induced increased S6 phosphorylation to a similar extent. This response was observed by the appearance of five new acidic forms of the protein, named a, b, c, and d-e, representing the incorporation of 1 to $5 \mathrm{~mol}$ of phosphate (36) (Fig. 2A and C, protein staining patterns; B and D, corresponding autoradiograms).

When the ${ }^{32} P_{i}$ was chased with unlabeled phosphate for 2 $h$ at $35^{\circ} \mathrm{C}$ in the continued presence of serum for normal cells, conditions that maintained the S6 kinase active $(6,44)$, overall S6 phosphorylation increased in both cases towards the most highly phosphorylated S6 derivatives (d and e) (Fig. $2 E$ versus $A$ and $G$ versus $C$ ), with a marked decrease in the less phosphorylated forms of S6 (a and b). However, when the incorporation of ${ }^{32} P_{i}$ into $S 6$ at the end of the pulse period was estimated as $100 \%$, normal cells showed a reduction of ${ }^{32} \mathrm{P}$-labeled S6 between 50 and $75 \%$ at the end of the 2-h chase period, determined by excising and counting the S6

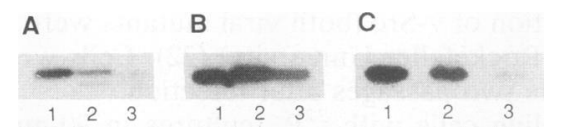

FIG. 3. Analysis of ${ }^{32} \mathrm{P}-\mathrm{S} 6$ turnover in transformation-defective mutants of v-Src. The turnover of ${ }^{32} \mathrm{P}$ in S6 from CEF (A), CEF-ts-NY72-4 (B), and CEF- $t d-N Y 3-15$ (C) was analyzed by pulse labeling of cells with ${ }^{32} \mathrm{P}$, followed by a chase period with nonradioactive $\mathrm{P}_{\mathrm{i}}$, as described in figure legend 2. Quiescent cultures of CEF, CEF-ts-NY72-4, and CEF-t $d$-NY3-15 at $41.5^{\circ} \mathrm{C}$ were pulsed with ${ }^{32} \mathrm{P}_{\mathrm{i}}(0.4 \mathrm{mCi} / \mathrm{ml})$ in phosphate-free DMEM for $2 \mathrm{~h}$ coincident with stimulation by shifting the temperature to $35^{\circ} \mathrm{C}$ plus the addition of $10 \%$ serum to CEF and CEF-td-NY3-15. S6 phosphorylation was analyzed by SDS-15\% PAGE, the gels were autoradiographed, and for quantification the $S 6$ bands were excised and radioactivity was determined by scintillation counting. Lanes 1 show the incorporation of ${ }^{32} \mathrm{P}_{\mathrm{i}}$ into $\mathrm{S} 6$ during the 2 -h pulse period. Lanes 2 show the labeling of S6 after a chase of ${ }^{32} \mathrm{P}$ for $2 \mathrm{~h}$, carried out at $35^{\circ} \mathrm{C}$ in complete DMEM and in the presence of $10 \%$ serum for CEF and CEF- $t d$-NY3-15 cells. Lanes 3 show the labeling of S6 after chase for $2 \mathrm{~h}$ at $41.5^{\circ} \mathrm{C}$ in complete DMEM and serum-deprived CEF and CEF-td-NY3-15 cells.

band from SDS gels in four different experiments (Fig. 2F versus $B$ and Fig. 3A, lane 2 versus lane 1 ). In contrast, transformed cells showed little or no decrease (0 to $20 \% ; n=$ 4 ) in the levels of ${ }^{32} \mathrm{P}$-S6 during the same chase period (Fig. $2 \mathrm{H}$ versus $\mathrm{D}$ and Fig. $3 \mathrm{~B}$, lane 2 versus lane 1 ). The meaning of those differences was confirmed by performing similar experiments in normal and transformed cells incubated for 2 $h$ without serum and at a nonpermissive temperature of $41.5^{\circ} \mathrm{C}$, respectively, conditions that were expected to inactivate S6 kinase (6). Under those conditions, cells returned to a quiescent state and S6 protein was dephosphorylated, as indicated by the predominance of the unphosphorylated form and the forms a and $b$ which contained only 1 and $2 \mathrm{~mol}$ of phosphate, respectively (Fig. 2I and K, Coomassie blue staining). Furthermore, the ${ }^{32} \mathrm{P}$ present in $\mathrm{S} 6$ was reduced by $80 \%$ in normal cells (Fig. 2J versus B and Fig. 3A, lane 3 versus lane 1) and, more important, by $40 \%$ in the transformed cells (Fig. 2L versus D and Fig. 3B, lane 3 versus lane 1). Since the rates of the S6 kinase inactivation were very similar for serum-deprived normal cells and for transformed cells transferred to a nonpermissive temperature (data not shown), it suggested that the S6 phosphatase activity was higher in normal than in transformed cells under those chase conditions. To exclude the possibility that the differences in the loss of ${ }^{32} \mathrm{P}-\mathrm{S} 6$ content between normal serum-stimulated and $\mathbf{v - S r c - t r a n s f o r m e d ~ c e l l s ~ s i m p l y ~ r e - ~}$ flected differences in ribosomal turnover, we performed a similar pulse-chase experiment with ${ }^{35}$ S $]$ methionine. No ribosomal degradation was detected during the chase period in which the differences in ${ }^{32} \mathrm{P}$-S6 turnover were detected (data not shown). Furthermore, a control study of the ATPase activity revealed no differences between normal and transformed cells (data not shown). These results strongly suggested that v-Src transformation inhibited S6 phosphatase activity.

To determine whether the above observations were specific to oncogenic transformation and not a consequence of viral infection, a pulse-chase experiment was carried out with CEF cells infected with $t d$-NY3-15, a transformationdefective mutant of the v-src oncogene. $t d-N Y 3-15$ encodes for a $160^{\mathrm{v}-s r c}$ with a deletion at the $\mathrm{N}$ terminus, such that the oncogene product retains tyrosine kinase activity but is cytosolic (22). The results showed that the CEF-td-NY3-15- 


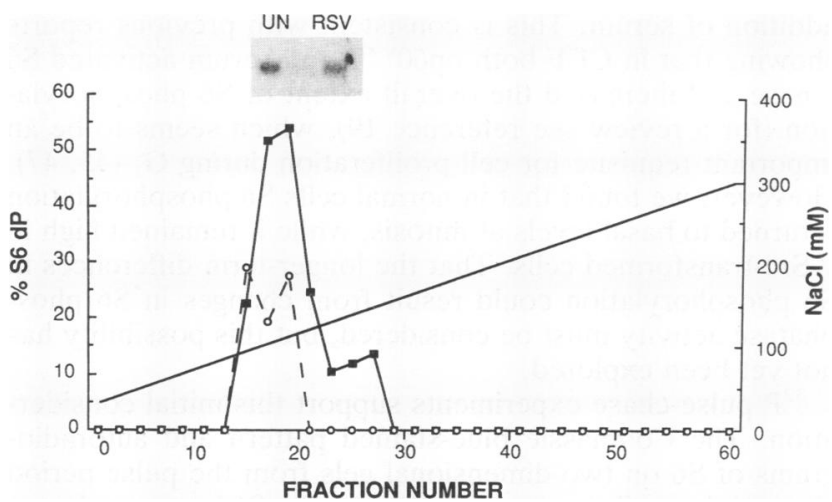

FIG. 4. S6 phosphatase activity in CEF and CEF-ts-NY72-4. Quiescent cultures of CEF and CEF-ts-NY72-4 at $41.5^{\circ} \mathrm{C}$ were stimulated by shifting both to $35^{\circ} \mathrm{C}$ plus the addition of $10 \%$ serum to CEF. After $4 \mathrm{~h}$, the supernatants of the cell homogenates, normalized for the amounts of protein, were applied to DEAE columns and the fractions were tested for S6 phosphatase activity with ${ }^{32} \mathrm{P}-40 \mathrm{~S}$ ribosomes $\left({ }^{32} \mathrm{P}-\mathrm{S} 6\right)$ in the absence or in the presence of inhibitor 2. 口, CEF; O, CEF-ts-NY72-4. The S6 phosphatase activity is presented as percent of S6 dephosphorylation (\% S6 dP). The peaks of S6 phosphatase activity were concentrated on small DEAE columns and loaded in SDS-15\% PAGE, and proteins were transferred to nitrocellulose and probed with the anti-PP1 polyclonal antibody. The immunoblot is shown in the inset. UN, uninfected CEF; RSV, CEF-ts-NY72-4.

infected cells behaved similarly to normal CEF cells, displaying a turnover of $60 \%$ of the phosphate incorporated to S6 during the chase period (Fig. 3A and C). Therefore, the lack of ${ }^{32} \mathrm{P}$-label turnover in $\mathrm{S} 6$ was specific to transformed cells in which the $160^{\mathrm{v}-s r c}$ is active and localized to the membrane and cytoskeleton.

The higher stability of the ${ }^{32} \mathrm{P}-\mathrm{S} 6$ in $\mathrm{v}$-Src-transformed cells suggested a decrease in normal levels of S6 phosphatase activity. To test for S6 phosphatase in vitro, CEF and CEF-ts-NY72-4 were stimulated for $4 \mathrm{~h}$ as described above, the same length of time as the pulse-plus-chase periods. Equal amounts of protein from the supernatants of each aliquot of cell lysates was analyzed by DEAE chromatography. The fractions were tested for S6 phosphatase activity by using phosphorylated $40 \mathrm{~S}$ ribosomal subunits as the substrate (see Materials and Methods). A major peak of phosphatase activity was eluted at $130 \mathrm{mM} \mathrm{NaCl}$ from normal and transformed cells (Fig. 4). Quantification of the activity showed that in $t s-\mathrm{NY} 72-4$-transformed cells the levels of S6 phosphatase were nearly threefold lower than those in normal cells. When the assay was performed in the presence of the PP1 inhibitor, inhibitor 2, the S6 phosphatase activity was completely blocked (Fig. 4, basal line), indicating that the enzyme was a PP1, in agreement with previous results $(2,39)$. The amounts of the $37-\mathrm{kDa}$ PP1 catalytic subunit recovered after DEAE chromatography, as measured by immunoblot analysis using a specific polyclonal anti-PP1 (10), were the same for normal and transformed cells (Fig. 4, inset), which suggests an inhibition of PP1 activity rather than a decrease of its expression.

We have further analyzed whether cellular transformation by $v$-Src could modify the expression of PP1. Since the catalytic subunits of PP1 and PP2A have several regions in their primary sequences that are identical (4), to discard the possibility that changes in the protein levels of the PP1-S6 phosphatase could be masked by fluctuations in PP2A, we

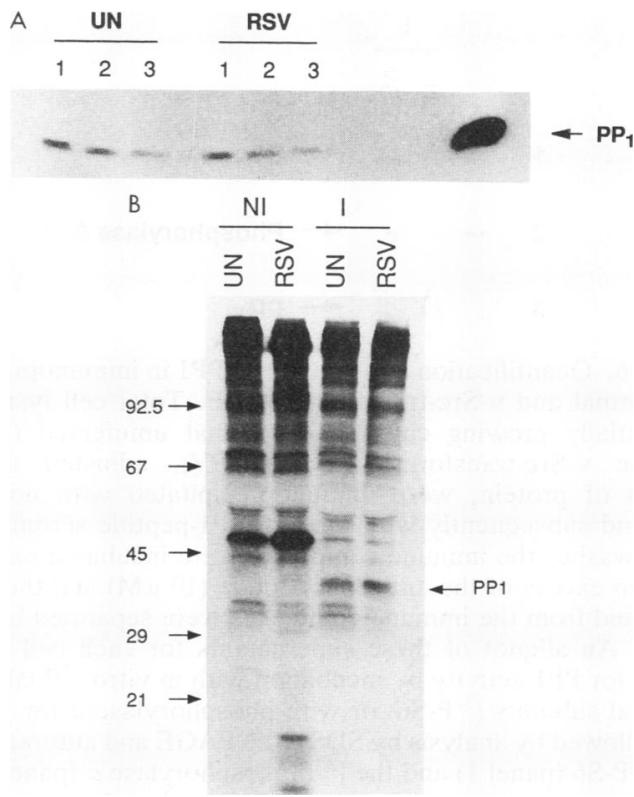

FIG. 5. (A) Immunoblotting of PP1 in lysates of normal and RSV-transformed cells. Immunoblotting was used to detect PP1 levels in total cellular proteins of normal uninfected (UN) and v-Src-transformed cells (RSV). Cells were directly lysed in $2 \times$ SDS sample buffer, and three samples, each containing equal amounts of protein $(100,50$, and $25 \mu \mathrm{g}$ [lanes 1,2 , and 3 , respectively]), from UN and RSV were loaded in SDS-15\% PAGE, transferred to nitrocellulose, and probed with the anti-PP1-peptide antibody, incubated with ${ }^{125} \mathrm{I}$-donkey anti-rabbit immunoglobulin $\mathrm{G}$, and subjected to autoradiography. The purified rabbit protein PP1 was used as a control (arrow). (B) Analysis of PP1 expression in normal and RSV-transformed cells. Exponentially growing cultures of normal uninfected (UN) and v-Src-transformed (RSV) cells were labeled with $\left[{ }^{35} \mathrm{~S}\right]$ methionine for $2 \mathrm{~h}$. Cell lysates, normalized for the amount of protein, were immunoprecipitated with a nonimmune serum (NI) or with the anti-PP1-peptide serum (I). The immunoprecipitates were analyzed by SDS-15\% PAGE, and a photograph of the fluorograph is shown. Molecular markers (in kilodaltons) are at the left. The PP1 (arrow) is at the right.

used, in the following experiments, an antiserum generated against the last 14 amino acids of the PP1 catalytic subunit, which have been shown to be specific for PP1 and which allow determination of phosphatase activity after immunoprecipitation (39). The steady-state expression of PP1 was measured by immunoblotting. Titration of total lysates of normal and v-Src-transformed cells showed that the amounts of PP1 were identical for both cell types (Fig. 5A). These results demonstrate that oncogenic transformation did not modify the steady-state levels of PP1 expression but did not exclude the possibility that $\mathrm{v}$-Src could alter its rate of synthesis. To test this possibility, PP1 was immunoprecipitated from equal amounts of protein cell lysates extracted from exponentially growing normal and v-Src-transformed CEF cells pulse-labeled for $2 \mathrm{~h}$ with $\left[{ }^{35}\right.$ S $]$ methionine. A 37-kDa protein band, corresponding to the catalytic subunit of PP1, was specifically immunoprecipitated (Fig. 5B). Since the intensity of this band was the same for both cell lysates, it can be argued that the rate of synthesis of PP1 was not altered by oncogenic transformation.

The bulk of data indicated that v-Src transformation inhibited PP1 specific activity; however, it cannot be excluded that a factor coeluting with the phosphatase in the 


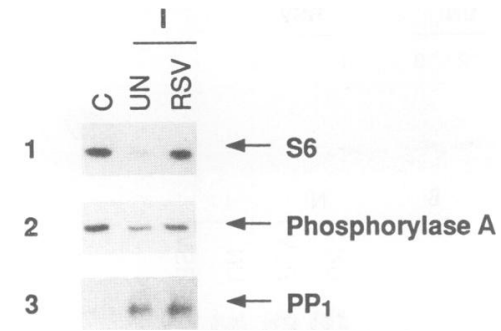

FIG. 6. Quantification and activity of PP1 in immunoprecipitates from normal and v-Src-transformed CEF. Total cell lysates from exponentially growing cultures of normal uninfected (UN) and wild-type v-Src-transformed CEF (RSV), adjusted for equal amounts of protein, were immunoprecipitated with nonimmune serum and subsequently with the anti-PP1-peptide serum (I); after several washes the immune complexes were incubated on ice for 1 $h$ with an excess of the antigenic peptide $(10 \mu \mathrm{M})$ and the proteins dissociated from the immune complexes were separated by centrifugation. An aliquot of these supernatants for each cell type was assayed for PP1 activity by incubation with in vitro ${ }^{32} \mathrm{P}$-labeled $40 \mathrm{~S}$ ribosomal subunits $\left.{ }^{32} \mathrm{P}-\mathrm{S} 6\right)$ or with phosphorylase $a$ for $10 \mathrm{~min}$ at $30^{\circ} \mathrm{C}$, followed by analysis by SDS-10\% PAGE and autoradiography of the ${ }^{32} \mathrm{P}-\mathrm{S} 6$ (panel 1) and the $\left.{ }^{32} \mathrm{P}\right]$ phosphorylase $a$ (panel 2). Line $\mathrm{C}$ shows the amounts of ${ }^{32} \mathrm{P}-\mathrm{S} 6$ or $\left[{ }^{32} \mathrm{P}\right]$ phosphorylase $a$ used in the assay. The other aliquot of the supernatants from each cell type was run in SDS-15\% PAGE, and proteins were transferred to nitrocellulose and probed with the anti-PP1-peptide serum (panel 3).

DEAE chromatography could be responsible for the decrease of activity. We have, therefore, taken advantage of the specific antipeptide serum and measured the activity and amounts of PP1 after immunoprecipitation. Cell lysates of both cell types, normalized for the amount of protein, were immunoprecipitated with an excess of antibody, and after several washes, the immune complexes were incubated on ice with an excess of the antigenic peptide $(10 \mu \mathrm{M})$ as described previously (39). Equal aliquots of the material displaced by the peptide from the immune complexes were then assayed for PP1 activity by using two substrates: in vitro phosphorylated $40 S$ ribosomal subunits containing ${ }^{32} \mathrm{P}$ $\mathrm{S} 6$, and in vitro-labeled $\left[{ }^{32} \mathrm{P}\right]$ phosphorylase $a$, a standard substrate for PP1 (14). The antigenic peptide released higher levels of PP1 activity from normal than from transformed cells, as tested on both substrates S6 and phosphorylase $a$ (Fig. 6, panels 1 and 2). The PP1 activity of normal versus transformed cells was significantly higher for S6 than for phosphorylase $a$, indicative of a PP1. The amount of PP1 in these samples was determined by immunoblotting of another aliquot of the same peptide-eluted immune complexes. It was found, once again, that normal and transformed cells expressed the same amounts of PP1 catalytic subunit (Fig. 6, panel 3). The results demonstrate that cellular transformation by v-Src decreased the activity of PP1 without affecting the protein levels of the enzyme.

\section{DISCUSSION}

Here, we present data demonstrating attenuation of the S6 protein phosphatase activity in v-Src-transformed CEF. Comparison was made between normal CEF cells and cells infected with either a temperature-sensitive virus ( $t s$ NY72-4) or a transformation-defective virus ( $t d-\mathrm{NY} 3-15)$.

S6 phosphorylation was increased during the $G_{1}$ phase of the growth cycle in ts-NY72-4-CEF transferred to a permissive temperature and in normal cells stimulated by the addition of serum. This is consistent with previous reports showing that in CEF both pp60 $0^{\text {v-src }}$ and serum activated S6 kinase and increased the overall extent of S6 phosphorylation (for a review see reference 19), which seems to be an important requisite for cell proliferation during $G_{1}(45,47)$. However, we found that in normal cells S6 phosphorylation returned to basal levels at mitosis, while it remained high in $v$-Src-transformed cells. That the longer-term differences in S6 phosphorylation could result from changes in S6 phosphatase activity must be considered, but this possibility has not yet been explored.

${ }^{32} \mathrm{P}$ pulse-chase experiments support this initial consideration. The Coomassie blue-stained pattern and autoradiograms of S6 on two-dimensional gels from the pulse period showed that $\mathrm{v}-\mathrm{Src}$ or serum activates the S6 kinase and, as a consequence, increases S6 phosphorylation. During the chase period, in normal serum-stimulated cells the reduction in the amount of ${ }^{32} \mathrm{P}$ label of S6 was greater than $50 \%$, as shown by the corresponding autoradiogram. In contrast, the overall state of S6 phosphorylation increased, as detected in the Coomassie blue-stained gel. This observation was consistent with a substantial level of S6 phosphatase activity in normal cells, and rapid cycling between phosphorylated and dephosphorylated S6, with activated S6 kinase predominating to accumulate the highly phosphorylated form of S6. In contrast, $t s-N Y 72-4$-transformed cells did not show a decrease in ${ }^{32} \mathrm{P}$ labeling of $\mathrm{S} 6$ during the chase period, revealing a new and important difference between normal and v-Srctransformed cells. The $t d-N Y 3-15$ gave the same response as normal cells. Moreover, no differences were detected in the rates of ribosomal turnover or in ATPase activities of normal and v-Src-transformed cells (data not shown). Therefore, the inhibition of ${ }^{32} \mathrm{P}-\mathrm{S} 6$ turnover in transformed cells must be a consequence of the oncogenic properties of v-Src. Changing the $t s-\mathrm{NY} 72-4$-infected cells from 35 to $41.5^{\circ} \mathrm{C}$ produced a rapid shift between the transformed and nontransformed states and inactivation of both the oncogenic protein pp60 $0^{t s-v-s r c}$ and the S6 kinase (6). Since the rates of S6 kinase inactivation during the chase protocol in serum-deprived normal cells and in transformed cells transferred to a nonpermissive temperature were very similar (data not shown), the differences in the rate of S6 dephosphorylation between both cells under these conditions were mainly a consequence of a higher activity of the S6 phosphatase in normal cells. Together, these results clearly indicate a lower level of in vivo S6 phosphatase activity in v-Src-transformed cells.

The specific activity of PP1 was lower in transformed cells. The S6 phosphatase activity detected after DEAE chromatography fractionation of cell lysates was blocked by inhibitor 2 and reactive with the PP1 antibody by immunoblotting, confirming that the S6 phosphatase was PP1, as previously reported $(2,39)$. Transformation reduced the PP1 specific activity, because there was approximately one-third of the S6 phosphatase activity but the same amount of PP1 detected in normal cells, as measured by immunoblotting after DEAE chromatography in both cell types. This result was supported by the analysis of the steady-state level of expression and the fact that the rate of synthesis of PP1 did not change after $v$-Src transformation of normal cells. It could be argued, however, that in transformed cells PP1 activity was reduced by complex formation between the catalytic subunit and cognate regulatory subunits or inhibitor proteins, e.g., inhibitor 1 and inhibitor $2(1,7,13)$. Gel filtration analysis of cell extracts from normal and transformed cells revealed identical elution profiles of PP1 activity (data not shown), suggesting that the reduced activity 
was not caused by the interaction of the catalytic subunit of PP1 with different cellular regulatory proteins. This is also supported by the protein patterns of PP1 immunoprecipitation from $\left[{ }^{35} \mathrm{~S}\right]$ methionine pulse-labeled cells, for which no differences were detected between normal and transformed cells.

It has been shown that phosphorylation of PP1 catalytic subunit by purified oncogenic tyrosine kinases could decrease its activity $(27,28,49)$. It was, therefore, an obvious possibility to explore. The immunoprecipitation of PP1 with the antipeptide serum from ${ }^{32} \mathrm{P}_{\mathrm{i}}$-labeled normal and $\mathrm{v}$-Srctransformed cells revealed a $37-\mathrm{kDa}$ protein that was phosphorylated to the same extent in both cell types, but phosphotyrosine was not detected in the immunoprecipitated $37-\mathrm{kDa}$ phosphoprotein, which was mainly serine phosphorylated in both normal and v-Src-transformed CEF (data not shown). Thus, the decrease of PP1 activity in transformed cells was not produced by direct $\mathrm{pp} 60^{\mathrm{v}-\mathrm{src}}$ phosphorylation. It is relevant to indicate that modulation of the S6 phosphatase in 3T3 cells by serum was reported to involve the PP1 catalytic subunit in association with two phosphoproteins of 26 and $48 \mathrm{kDa}$ (39). In the fission yeast, mutations in dis2 and sds21, the PP1 homologs in this species, are suppressed by Sds22. The interaction alters the substrate specificity because the complex of Sds22:PP1 has histone phosphatase but not phosphorylase phosphatase activity (43). The Sds22 protein is reported to be phosphorylated in cells, and it is conceivable that the Sds 22 homolog in mammals is the $48-\mathrm{kDa}$ phosphoprotein that coimmunoprecipitates with PP1. Targeting subunits have been also implicated in PP1 specificity in skeletal and smooth muscle (1). We also observed a selective effect of PP1 inhibition in transformed cells, since the activity of PP1 in normal cells for ${ }^{32} \mathrm{P}-\mathrm{S} 6$ was higher than that detected for $\left[{ }^{32} \mathrm{P}\right]$ phosphorylase $a$ compared with PP1 activity in transformed cells. We can speculate that the regulation of PP1 observed here specifically reduced S6 phosphatase activity, but constant phosphorylase phosphatase activity in $\mathrm{v}$-Src-transformed cells could involve a posttranslational modification, i.e., phosphorylation or dephosphorylation, of a targeting and/or regulatory protein associated with the PP1 catalytic subunit. Here, we did not detect the 26- and 48-kDa phosphoproteins, perhaps revealing differences in the regulatory mechanisms of PP1 of birds and mammals. Nevertheless, a causal relationship between phosphorylation of the 37- or the 26- and $48-\mathrm{kDa}$ proteins and the activity of PP1 now needs to be established.

The measurements of the activity and amounts of PP1 determined after its immunoprecipitation from normal and transformed cells with the anti-PP1 peptide serum showed that while the amounts of PP1 catalytic subunit were identical for both cell types, v-Src provoked an inhibition of this phosphatase activity, clearly demonstrating that cellular transformation by v-Src inhibits PP1-specific activity compared with the activity found with serum growth factors in normal cells.

In view of the fact that PP1 plays a crucial role in growth control $(8,17,18,20,23,31,37)$ and that insulin and growth factors are reported to stimulate PP1 activity $(11,38)$, the inhibition of PP1 by $\mathrm{V}$-Src could be relevant in the mechanisms of aberrant cellular growth induced by this oncogene. In addition, since PP1 is highly expressed in the nuclei (7) and many transcription factors are regulated by phosphorylation (25), the inhibition of PP1 might be implicated, in part, in the alteration of gene expression provoked by $\mathrm{v}$-Src.

\section{ACKNOWLEDGMENTS}

We thank R. L. Erikson (Harvard University) in whose laboratory J.M.-P. carried out the initial experiments. The authors are very grateful to A. R. Olivier and G. Thomas (Friedrich Miescher Institute) for their suggestions and gift of anti-PP1 antibody that made it possible to obtain these results. We also thank M. V. Carretero and J. A. Fresno-Vara for their help, S. Alemany, B. Rudkin, J. Gonzalez, I. Sandoval, S. Kozma, and G. Thomas for critical review of the manuscript, and $C$. Wiedmer for help in editing.

This research was supported by grants from DGICYT (PM89-0017 and PB92-0116), CAM (C263/91), and NATO (0010/89) to J.M.-P. and PHS grant DK-31374 to D.L.B. B.B. was supported by a fellowship from the Gobierno Vasco.

\section{REFERENCES}

1. Alessi, D., L. K. Macdougall, M. M. Sola, M. Ikebe, and P. Cohen. 1992. The control of protein phosphatase-1 by targeting subunits. Eur. J. Biochem. 210:1023-1035.

2. Andres, J. L., and J. L. Maller. 1989. Purification and characterization of a novel protein phosphatase highly specific for ribosomal protein S6. J. Biol. Chem. 264:151-156.

3. Ballou, L. M., P. Jenö, and G. Thomas. 1988. Protein phosphatase $2 \mathrm{~A}$ inactivates the mitogen-stimulated S6 kinase from Swiss 3T3 cells. J. Biol. Chem. 263:1188-1194.

4. Berndt, N., D. G. Campbell, F. B. Caudwell, P. Cohen, E. F. da Cruz e Silva, O. B. da Cruz e Silva, and P. T. W. Cohen. 1987. Isolation and sequence analysis of a cDNA clone encoding a type-1 protein phosphatase catalytic subunit: homology with protein phosphatase 2A. FEBS Lett. 223:340-346.

5. Blenis, J., and R. L. Erikson. 1984. Phosphorylation of the ribosomal protein $\mathrm{S} 6$ is elevated in cells transformed by a variety of tumor viruses. J. Virol. 50:966-969.

6. Blenis, J., and R. L. Erikson. 1985. Regulation of a ribosomal protein $\mathrm{S} 6$ kinase activity by the Rous sarcoma virus transforming protein, serum, or phorbol ester. Proc. Natl. Acad. Sci. USA 82:7621-7625.

7. Bollen, M., and W. Stalmans. 1992. The structure, role, and regulation of type 1 protein phosphatases. Crit. Rev. Biochem. Mol. Biol. 27:227-281.

8. Boohr, R., and D. Beach. 1989. Involvement of type 1 protein phosphatase encoded by bws $1^{+}$in fission yeast mitotic control. Cell 57:1009-1016.

9. Brautigan, D. L. 1992. Great expectations: protein tyrosine phosphatases in cell regulation. Biochim. Biophys. Acta 1114: 63-77.

10. Brautigan, D. L., P. A. Gruppuso, and M. Mumby. 1986. Protein phosphatase type-1 and type-2A catalytic subunits both bind inhibitor-2 and monoclonal immunoglobulins. J. Biol. Chem. 261:14924-14928.

11. Chan, C. P., S. J. McNall, E. G. Krebs, and E. H. Fischer. 1988. Stimulation of protein phosphatase activity by insulin and growth factors in 3T3 cells. Proc. Natl. Acad. Sci. USA 85:6257-6261.

12. Chen, J., B. L. Martin, and D. L. Brautigan. 1992. Regulation of protein Ser-Thr phosphatase type-2A by tyrosine phosphorylation. Science 257:1261-1264.

13. Cohen, P. 1989. The structure and regulation of protein phosphatases. Annu. Rev. Biochem. 58:453-508.

14. Cohen, P., S. Alemany, B. A. Hemmings, T. J. Resink, P. Stralfrors, and H. Y. Lim-Tung. 1988. Protein phosphatase-1 and protein phosphatase-2A from rabbit skeletal muscle. Methods Enzymol. 159:390-409.

15. Cohen, P., and P. T. W. Cohen. 1989. Protein phosphatases come of age. J. Biol. Chem. 264:21435-21438.

16. Cohen, P. T. W., N. D. Brewis, V. Hughes, and D. J. Mann. 1990. Protein serine/threonine phosphatases; an expanding family. FEBS Lett. 268:355-359.

17. Doonan, J. H., and N. R. Morris. 1989. The bimG gene of Aspergillus nidulans, required for completion of anaphase, encodes a homolog of mammalian phosphoprotein phosphatase 1. Cell 57:987-996.

18. Durfee, T., K. Becherer, P.-L. Chen, S.-H. Yeh, Y. Yang, A. E. 
Kilburn, W.-H. Lee, and S. J. Elledge. 1993. The retinoblastoma protein associates with the protein phosphatase type 1 catalytic subunit. Genes Dev. 7:555-569.

19. Erikson, R. L. 1991. Structure, expression, and regulation of protein kinases involved in the phosphorylation of ribosomal protein S6. J. Biol. Chem. 266:6007-6010.

20. Fernandez, A., D. L. Brautigan, and N. J. C. Lamb. 1992. Protein phosphatase type 1 in mammalian cell mitosis: chromosomal localization and involvement in mitosis exit. J. Cell. Biol. 116:1421-1430.

21. Gómez, N., and P. Cohen. 1991. Dissection of the protein kinase cascade by which nerve growth factor activates MAP kinases. Nature (London) 353:170-173.

22. Gross, F. R., E. A. Garber, D. Pellman, and H. Hanafusa. 1984. A short sequence in the $\mathrm{p} 60^{s r c} \mathrm{~N}$ terminus is required for $\mathrm{p} 60^{\text {src }}$ myristylation and membrane association and for cell transformation. Mol. Cell. Biol. 4:1834-1842.

23. Hollingsworth, R. E., C. E. Hensey, and W.-H. Lee. 1993. Retinoblastoma protein and the cell cycle. Curr. Opin. Genet. Dev. 3:55-62.

24. Hunter, T. 1989. Protein-tyrosine phosphatases: the other side of the coin. Cell 58:1013-1016.

25. Hunter, T., and M. Karin. 1992. The regulation of transcription by phosphorylation. Cell 70:375-387.

26. Hunter, T., and B. M. Sefton. 1980 . Transforming gene product of Rous sarcoma virus phosphorylates tyrosine. Proc. Natl. Acad. Sci. USA 77:1311-1315.

27. Johansen, J. W., and T. S. Ingebritsen. 1986. Phosphorylation and inactivation of protein phosphatase 1 by $\mathrm{pp} 60^{\nu-s r c}$. Proc. Natl. Acad. Sci. USA 83:207-211.

28. Johansen, J. W., and T. S. Ingebritsen. 1987. Effects of phosphorylation of protein phosphatase 1 by $\mathrm{pp}^{2} 0^{\nu-s r c}$ on the interaction of the enzyme with substrates and inhibitor proteins. Biochim. Biophys. Acta 928:63-75.

29. Kamibayashi, C., R. Estes, C. Slaughter, and M. Mumby. 1991. Subunit interactions control protein phosphatase 2A. J. Biol. Chem. 266:13251-13260.

30. Laemmli, U. K. 1970. Cleavage of structural proteins during the assembly of the head of bacteriophage T4. Nature (London) 227:680-685.

31. Ludlow, J. W., C. L. Glendening, D. M. Livingston, and J. A. DeCaprio. 1993. Specific enzymatic dephosphorylation of the retinoblastoma protein. Mol. Cell. Biol. 13:367-372.

32. Martin, B. L., C. L. Shriner, and D. L. Brautigan. 1991. Modulation of type-1 protein phosphatase by synthetic peptides corresponding to the carboxyl terminus. FEBS Lett. 285:6-10.

33. Martín-Pérez, J., B. Belandia, M. V. Carretero, and J. A Fresno. 1991. Papel biologico de la fosforilacion proteica en el control del crecimiento de celulas normales y transformadas por el virus del sarcoma de Rous, p. 265-282. In J. C. Lacal and M. Barbacid (ed.), Bases moleculares del cancer, aplicaciones clinicas y desarrollo tecnologico. Farmaindustria, Madrid.

34. Martín-Pérez, J., B. B. Rudkin, M. Siegmann, and G. Thomas.
1986. Activation of ribosomal protein S6 phosphorylation during meiotic maturation of Xenopus laevis oocytes: in vitro ordered appearance of S6 phosphopeptides. EMBO J. 5:725-731.

35. Martín-Pérez, J., M. Siegmann, and G. Thomas. 1984. EGF, PDGF $_{2 \alpha}$ and insulin induce the phosphorylation of identical S6 peptides in Swiss mouse 3T3 cells: effect of cAMP on early sites of phosphorylation. Cell 34:387-394.

36. Martín-Pérez, J., and G. Thomas. 1983. Ordered phosphorylation of $40 \mathrm{~S}$ ribosomal protein S6 after serum stimulation of quiescent 3T3 cells. Proc. Natl. Acad. Sci. USA 80:926-930.

37. Ohkura, H., N. Kinoshita, S. Miyatani, T. Toda, and M. Yanahida. 1989. The fission yeast dis ${ }^{+}$gene required for chromosomal disjoining encodes one of two putative type 1 protein phosphatases. Cell 57:997-1007.

38. Olivier, A. R., L. M. Ballou, and G. Thomas. 1988. Differential regulation of $\mathrm{S} 6$ phosphorylation by insulin and epidermal growth factor in Swiss mouse 3T3 cells: insulin activation of type 1 phosphatase. Proc. Natl. Acad. Sci. USA 85:4720-4724.

39. Olivier, A. R., and G. Thomas. 1990. Three forms of phosphatase type 1 in Swiss 3T3 fibroblasts. J. Biol. Chem. 265: 22460-22466.

40. Pot, D. A., and J. E. Dixon. 1992. A thousand and two protein tyrosine phosphatases. Biochim. Biophys. Acta 1136:35-43.

41. Schlessinger, J., and A. Ullrich. 1992. Growth factor signaling by receptor tyrosine kinases. Neuron 9:383-391.

42. Siegmann, M., and G. Thomas. 1987. Separation of multiple phosphorylated forms of $40 \mathrm{~S}$ ribosomal protein S6 by twodimensional polyacrylamide gel electrophoresis. Methods Enzymol. 146:362-369.

43. Stone, E. M., H. Yamano, N. Kinoshita, and M. Yanagida. 1993. Mitotic regulation of protein phosphatases by fission yeast sds22 protein. Curr. Biol. 3:13-26.

44. Sweet, L. J., D. A. Alcorta, and R. L. Erikson. 1990. Two distinct enzymes contribute to biphasic S6 phosphorylation in serum-stimulated chicken embryo fibroblasts. Mol. Cell. Biol. 10:2787-2792.

45. Thomas, G. 1991. Molecular and biochemical characterization of the mitogen-activated S6 kinase. NATO ASI Ser. Soc. H Cell Biol. 56:375-388.

46. Thomas, G. 1992. MAP kinase by any other name smells just as sweet. Cell 68:3-6.

47. Thomas, G., J. Martín-Pérez, M. Siegmann, and A. M. Otto. 1982. The effect of serum, EGF, $\mathrm{PDFG}_{2 \alpha}$ and insulin on S6 phosphorylation and the initiation of protein and DNA synthesis. Cell 30:235-242.

48. Tonks, N. K., and P. Cohen. 1984. The protein phosphatases involved in cellular regulation. Identification of the inhibitor-2 phosphatases in rabbit skeletal muscle. Eur. J. Biochem. 145: 65-70.

49. Villa-Moruzzi, E., P. D. Zonca, and J. W. Crabb. 1991. Phosphorylation of the catalytic subunit of type-1 protein phosphatase by the $v$-abl tyrosine kinase. FEBS Lett. 293:67-71. 